\title{
Emergency cricothyroidotomy and conversion tracheostomy in a patient with COVID-19: a case report
}

\author{
YF Lau *, MRCSEd, Fergus KC Wong, FRCSEd (ORL), Peter KC Kwan, FRCSEd (ORL) \\ Department of Ear, Nose and Throat, Pamela Youde Nethersole Eastern Hospital, Hong Kong \\ * Corresponding author: lauyukfai@gmail.com
}

published on $7 \mathrm{Apr}$

2021 at www.hkmj.org.

Hong Kong Med J 2021;27:140-1

https://doi.org/10.12809/hkmj209062

\section{Case report}

In June 2020, a 56-year-old man with ankylosing spondylitis, fixed flexion cervical spine deformity, and restrictive lung disease was admitted to our hospital with symptoms of pneumonia. A diagnosis of coronavirus disease 2019 (COVID-19) was confirmed by positive polymerase chain reaction test results from throat swab and sputum samples. The patient was treated with a triple combination of interferon beta-1b, lopinavir and ritonavir with clofazimine, in accordance with local recommendations. ${ }^{1}$ The patient developed respiratory failure with upper airway obstruction, requiring endotracheal intubation and mechanical ventilation. Intubation attempts failed and the patient developed oxygen desaturation. Bedside cricothyroidotomy was performed immediately with a surgical scalpel. A Portex Blue Line size 6.0 cuffed tracheostomy tube (Smiths Medical) was inserted. Full personal protective equipment (PPE), including N95 respirator, water-proof gown, face shield, and goggles, was worn by the resuscitation team during the bedside procedure.

On the same day, after the patient's oxygen

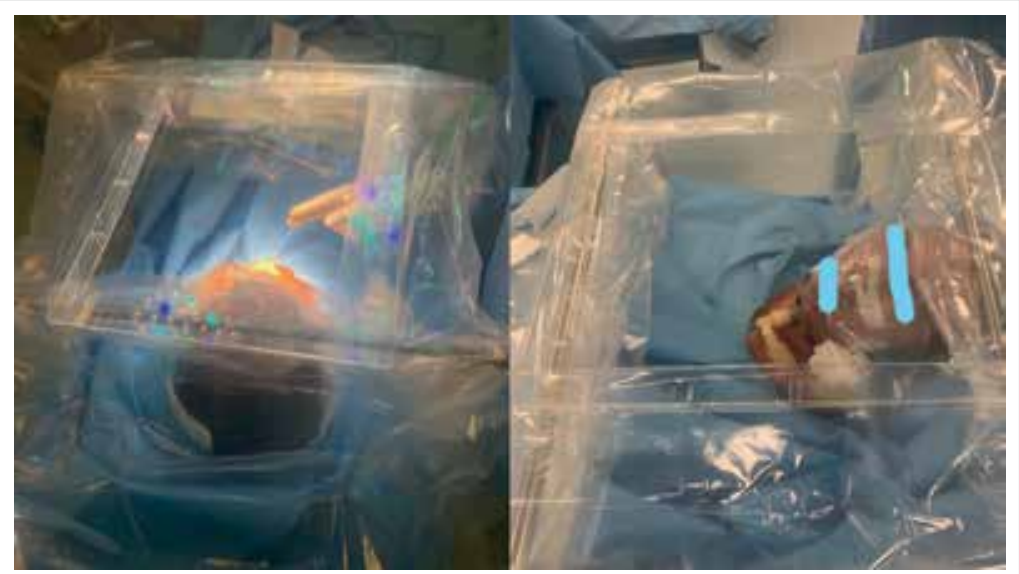

FIG I. Photograph showing a 'barrier box' used during conversion tracheostomy on a patient with coronavirus disease 2019. The box, made from sterile clear acrylic and Steri-Drape (3M) plastic drapes, protects the surgical staff from aspirates while allowing clear visibility of the surgical site saturation stabilised, conversion tracheostomy was performed in a negative pressure operating theatre. Full PPE was worn by the operating team. Because of the patient's flexed cervical spine deformity, three pillows were needed to support the head. A 'barrier box' was set up over the head and neck using two horizontal anaesthetic screen support bars at the cephalic and caudal ends of the surgical field. Sterile clear acrylic $(450 \mathrm{~mm} \times 350 \mathrm{~mm})$ was placed on top of the bars, and four Steri-Drape (3M) plastic drapes were attached, one on each side (Fig 1). Local anaesthetic (2\% lidocaine with 1:80 000 epinephrine; Xylestesin-A [3M]) was injected around the incision site. Electrocautery was avoided and only cold steel instruments were used for dissection. Haemostasis was achieved by temporary local application of 1:20000 adrenaline gauze. Before the trachea incision, a muscle relaxant was given and ventilation was stopped. A Portex Blue Line Ultra size 7.5 cuffed tracheostomy tube (Smiths Medical) was inserted and the cuff was inflated. Ventilation resumed only after closed ventilatory circuit was achieved. The cricothyroidotomy tube was then removed and the wound was repaired (Fig 2).

The patient remained stable after the surgical procedures. There were no surgical complications. None of the healthcare workers involved in the cricothyroidotomy or tracheostomy tested positive for COVID-19 within 14 days after the procedures.

\section{Discussion}

Up to $20 \%$ of patients with COVID-19 have severe or critical cases, and a significant proportion required mechanical ventilation. ${ }^{2}$ Tracheostomy is seldom needed as these critically ill patients either succumb or recover after weeks of mechanical ventilation, without the need for prolonged intubation. ${ }^{3}$ However, some of these patients may require emergency surgical airway control. Aerosolgenerating procedures, including endotracheal intubation, cricothyroidotomy, and tracheostomy, are leading causes of viral transmission and pose a substantial risk of viral infection to the healthcare workers despite appropriate PPE. ${ }^{4}$ 


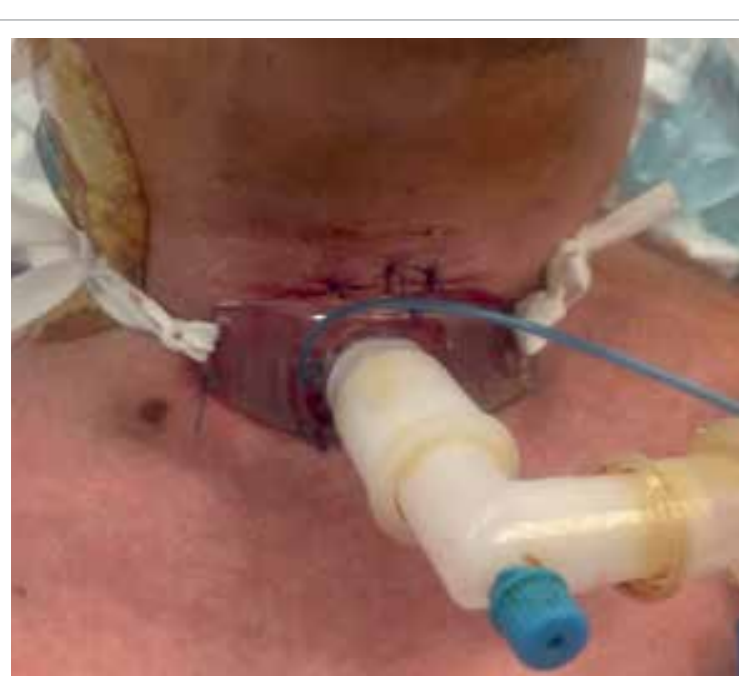

FIG 2. Photograph of a patient with coronavirus disease 2019 after conversion tracheostomy showing the tracheostomy tube in situ and the closed cricothyroidotomy wound until the tracheostomy tube was inserted and the closed ventilatory system is formed, to prevent the dissemination of the virus.

This case report highlights critical procedural safety precautions during tracheostomy, including the use of a 'barrier box', avoidance of electrocautery, and pausing ventilation before incising the trachea, which can minimise infection risks to healthcare workers.

\section{Author contributions}

Concept or design: All authors.

Acquisition of data: YF Lau.

Analysis or interpretation of data: YF Lau.

Drafting of the manuscript: YF Lau.

Critical revision of the manuscript for important intellectual content: FKC Wong, PKC Kwan.

All authors had full access to the data, contributed to the study, approved the final version for publication, and take responsibility for its accuracy and integrity.

\section{Conflicts of interest}

In an airway emergency involving a patient with COVID-19, cricothyroidotomy rather than tracheostomy should be done at the bedside if the patient is unfit to be transferred to the operating theatre. Cricothyroidotomy is a simple and quick bedside procedure; however, it still poses an infection risk for healthcare providers. Limiting the number of healthcare personnel involved in the procedure may reduce the risk of transmission. Placing a portable local exhaust ventilation unit next to the patient and pausing ventilation during the incision, until the closed ventilation circuit is formed, can lower the risk further. Scalpel rather than needle cricothyroidotomy is recommended, because jet ventilation is required after needle cricothyroidotomy, increasing the risk of airborne infection. Conversion tracheostomy can be done more safely after airway control, with staff and theatre better prepared.

Wei et $\mathrm{al}^{5}$ previously described safety precautions for performing tracheostomy in patients with severe acute respiratory syndrome, including using PPE, performing tracheostomy in a negativepressure room, and completely paralysing the patient during the procedure. We took extra precautions to further minimise the risk of COVID-19 infection to medical staff. First, we used a sterile 'barrier box' to minimise aerosol exposure. Second, we used a concentrated local anaesthetic and vasoconstriction to create a bloodless surgical field, lessening the need for aerosol-generating electrocautery. Third, we paused ventilation before trachea incision
The authors have no conflicts of interest to disclose.

\section{Funding/support}

This case report received no specific grant from any funding agency in the public, commercial, or not-for-profit sectors.

\section{Ethics approval}

The patient was treated in accordance with the Declaration of Helsinki. The patient provided informed consent for all treatments and procedures, and consent for publication.

\section{References}

1. Hung IF, Lung KC, Tso EY, et al. Triple combination of interferon beta-1b, lopinavir-ritonavir, and ribavirin in the treatment of patients admitted to hospital with COVID-19: an open-label, randomised, phase 2 trial. Lancet 2020;395:1695-704.

2. World Health Organization. Report of the WHO-China Joint Mission on coronavirus disease 2019 (COVID-19). 28 Feb 2020. Available from: https://www.who.int/docs/ default-source/coronaviruse/who-china-joint-mission-oncovid-19---final-report-1100hr-28feb2020-11mar-update. pdf. Accessed 7 Jul 2020.

3. Yang $\mathrm{X}, \mathrm{Yu} \mathrm{Y}, \mathrm{Xu}$ J, et al. Clinical course and outcomes of critically ill patients with SARS-CoV-2 pneumonia in Wuhan, China: a single-centered retrospective, observational study. Lancet Respir Med 2020;8:475-81.

4. McGrath BA, Brenner MJ, Warrillow SJ, et al. Tracheostomy in the COVID-19 era: global and multidisciplinary guidance. Lancet Respir Med 2020;8:717-25.

5. Wei WI, Tuen HH, Ng RW, Lam LK. Safe tracheostomy for patients with severe acute respiratory syndrome. Laryngoscope 2003;113:1777-9. 